\title{
Analysing half-lives for pesticide dissipation in plants
}

\author{
Jacobsen, R.E.; Fantke, Peter; Trapp, Stefan
}

Published in:

S A R and Q S A R in Environmental Research

Link to article, DOI:

10.1080/1062936X.2015.1034772

Publication date:

2015

Document Version

Peer reviewed version

Link back to DTU Orbit

Citation (APA):

Jacobsen, R. E., Fantke, P., \& Trapp, S. (2015). Analysing half-lives for pesticide dissipation in plants. $S A R$ and Q S A R in Environmental Research, 26(4), 325-342. https://doi.org/10.1080/1062936X.2015.1034772

\section{General rights}

Copyright and moral rights for the publications made accessible in the public portal are retained by the authors and/or other copyright owners and it is a condition of accessing publications that users recognise and abide by the legal requirements associated with these rights.

- Users may download and print one copy of any publication from the public portal for the purpose of private study or research.

- You may not further distribute the material or use it for any profit-making activity or commercial gain

- You may freely distribute the URL identifying the publication in the public portal

If you believe that this document breaches copyright please contact us providing details, and we will remove access to the work immediately and investigate your claim. 


\section{Analyzing Half-Lives for Pesticide Dissipation in Plants}

2 Rune Emil Jacobsen ${ }^{1}$, Peter Fantke ${ }^{2}$ and Stefan Trapp ${ }^{1, *}$

31 Technical University of Denmark, Department of Environmental Engineering, Miljøvej bd. 113, 42800 Kongens Lyngby, Denmark

52 Technical University of Denmark, Department of Management Engineering, Produktionstorvet 6 424, 2800 Kongens Lyngby, Denmark

* corresponding author sttr@env.dtu.dk, Tel +45 4525 1622, Fax +45 45932850

\section{Abstract}

Overall dissipation of pesticides from plants is frequently measured, but the contribution of individual loss processes is largely unknown. We use a pesticide fate model for the quantification of dissipation by processes other than degradation. The model was parameterized using field studies. Scenarios were established for Copenhagen/Denmark and Shanghai/PR China and calibrated with measured results. The simulated dissipation rates of 42 pesticides were then compared to measured overall dissipation from field studies with tomato and wheat. The difference between measured overall dissipation and calculated dissipation by non-degradative process should ideally be contributable to degradation in plants. In $11 \%$ of the cases, calculated dissipation was above the measured dissipation. For the remaining cases, the non-explained dissipation ranged from $30 \%$ to $83 \%$, depending on crop type, plant part and scenario. Accordingly, degradation is the most relevant dissipation process for these 42 pesticides, followed by growth dilution. Volatilization was less relevant, which can be explained by the design of plant protection agents. Uptake of active compound from soil into plants leads to a negative dissipation process (i.e. a gain) that is difficult to quantify because it depends largely on interception, precipitation and plant stage. The process is in particular relevant for soluble compounds.

Keywords: Plant protection; plant uptake; degradation; metabolism; transformation; herbicides; insecticides; fungicides; modeling; simulation. 


\section{Introduction}

Pesticides are used with the primary objective to control agricultural pests and to increase crop yield. It is estimated that for example the economic return of the usage of pesticides from the past 60 years in the USA is around $\$ 16$ billion per year [1,2]. The grain production in India increased nearly fourfold over a period of 50 years from 1948, and similar patterns are found in countries all over the world [1,3]. With a projected increase in the world population from 6.1 billion in 2000 to 9.1 billion in 2050 the pressure on high crop yields will be even growing [4]. However, pesticides have by definition toxic properties and can distribute within several media like air, soil and water, followed by uptake into the tissues of living organisms including humans where they can be subject to bioaccumulation and lead to negative effects [5-7]. The predominant exposure pathway for the general public is thereby the intake of pesticides via residues in treated food crops [8,9]. In 2008, a study investigating the presence of pesticides in food commodities throughout the 27 European Union member states and Norway and Iceland with 11610 samples found residues of 365 different pesticides in fruits and vegetables [10]. The percentage of samples with residues of two or more pesticides present was 27\%. Similar studies in 1997 and 2007 found the percentage of samples containing residues of several pesticides to be $15 \%$ and $26 \%$, respectively, underlining the presence of pesticide residues in food commodities [10].

As controlled usage of agricultural pesticides is important, modeling of pesticide distribution in crops is a key tool in limiting the overuse of pesticides and quantifying human exposure as relevant component in human safety assessments. Several models estimating the uptake and translocation of pesticides into food crops have been developed and an overview of such models is given elsewhere [11-14].

All mechanistic plant uptake models critically rely on information describing different processes contributing to dissipation from the treated crops and represent potential dissipation processes typically in terms of process-specific rate coefficients or half-lives. Moreover, results of such models (i.e. residual concentrations of pesticides in crop harvest) are highly sensitive to information regarding specific dissipation processes, such as degradation. However, information for individual dissipation processes in plants is often not available from experimental data. Instead, experimental studies mostly report aggregated dissipation estimated from measuring the evolution of the overall residual pesticide concentration in the plant over time. Fantke and Juraske [15] compiled a database of such reported pesticide dissipation half-lives in plants based on the analysis of 811 studies 
published between 1956 and 2012 with a total of 4513 experimental half-lives reported for 183 plant species. Despite the magnitude of this database, dissipation half-lives for many pesticide-crop combinations are still not available, but need to be estimated instead. As a rule of thumb, the disappearance half time from plants is four times faster than that from soil [16]. However, this easy rule was disputed by use of other data sets, and a log-log regression for the relation between disappearance in soil and plants was suggested instead [17]. A recent study showed that also plant characteristics, temperature, and study conditions affect the overall dissipation of pesticides in plants [18]. Process-specific information along with an insight of which processes are predominantly contributing to overall dissipation in plants is still not available but required by most mechanistic plant uptake models for estimating pesticide residues in harvested products. Such information would furthermore be useful for interpreting the rather large variability of measured data [15].

Collins et al. [19] reviewed key loss processes in modeling plant uptake of organic chemicals and found metabolism, photolytic degradation on plant surfaces, volatilization to air and dilution due to plant growth to be potentially significant processes. Of these, volatilization from plant surfaces to air is a well-known loss process contributing to overall dissipation from plants. Van den Berg et al. [20] report that the loss of pesticides to air after application as a function of pesticide, soil and crop properties, application technique and environmental conditions ranges from a few percentages up to $60 \%$ of the total applied pesticide mass. Wolters et al. [21] identified volatilization as one of the primary processes determining dispersion of pesticides throughout the general environment and Riederer [22] described the equations for volatilization from leaves.

Growth is a dissipation process that does not reduce compounds' mass but leads to lower concentrations by dilution. Hopkins et al. [23] found the loss through growth dilution alone could account for $60 \%$ to $80 \%$ of initial pesticide deposit and Miles et al. [24] estimated that growth dilution is of equal importance for dissipation as degradation and volatilization. Growth of annual plants follows a logistic curve, and typical doubling times for plant volume during the exponential phase range from 3 days for maize in May to 3 weeks for typical meadows in summer (own observations, non-published). Growth can therefore be a very efficient dissipation process when pesticides are applied during the exponential growth phase.

Degradation has been reported to be one of the predominant dissipation processes [25-27], but measured values are rarely available. Komossa et al. [28] compiled values for the metabolism of 
xenobiotics in cultures of suspended soybean and wheat cells. In these tests, there is often seen rapid degradation within short time periods. For example, more than $90 \%$ of the herbicide $2,4-\mathrm{D}$ was degraded to mostly polar metabolites within $48 \mathrm{~h}$ by wheat cells [28]. These cell cultures are quite different from intact plants, and parameters like substrate availability and temperature are optimal for degradation, while endophytic microbes and photolysis do not contribute to degradation in such experiments. The transferability of these results to field conditions is thus uncertain. However, in vivo degradation by plants is difficult to track due to the complexity of processes. Radiolabeled compounds have been used in several studies, e.g., Trapp et al. [29], but this method is restricted to laboratory or controlled lysimeter studies. In those studies, the concentration of transformation products is usually higher in plants than in soil. This indicates fast metabolism by plant cells, but polar metabolites may concentrate in plants due to translocation from soil.

Even though individual dissipation processes are known and described, there is a lack of knowledge on the contribution of these processes to the overall dissipation of pesticides from plants. Hence, an accurate model able to describe the dissipation through both degradation and non-degradation processes including volatilization and growth dilution is needed as resource-efficient element for improving risk and comparative impact assessment models used by industry and regulating authorities to reduce the unintentional impacts of pesticide usage. To address the need of applying such a combined, process-specific model, the three main objectives of this study are (i) to parameterize a dynamic soil-plant model for pesticides applied to plant and soil and to simulate the non-degradation processes of pesticide dissipation, (ii) to compare simulated pesticide dissipation in crops with measured overall dissipation data from published literature and (iii) to estimate the contribution of degradation, growth dilution and volatilization to the overall loss of pesticides from plants.

\section{Methods}

\section{Model description}

A coupled soil and plant uptake modeling framework was applied and extended that describes the transport of water and solutes in soil and plants. The tipping buckets approach is applied for water and solute transport in soil, and the dynamic plant uptake model ("Cascade model") is used to calculate the uptake, transport and fate of compounds in plants. 
The tipping buckets model is based on the principals of water budgeting in discretized soil layers [30-32]. The dynamic plant uptake model is well-described and consists of the four plant compartments roots, stem, leaves and fruits [33-35]. The resulting differential equations are solved analytically. The simulation time is divided into $n$ periods, all having specific input data and corresponding to the periods of the tipping buckets algorithm. This allows an easy coupling of soil and plant modules and also the simulation of non-linear scenarios. For the current study the simulated time was divided into 100 periods of one day lengths. Weekly precipitation events were introduced to reflect the non-constant rain pattern in temperate climates. Spray application of pesticides on leaves and soil surface was implemented as pulse source term. The combined soil and plant uptake model is implemented in a Microsoft Excel spreadsheet and is taught in course 12906 at DTU. It was used and validated by Trapp and Eggen [36] for polar organic compounds and by Højrup [37] for ionizing organic compounds. The model has previously been evaluated by Prosser et al. [38], where it was concluded that the approach is able to predict the uptake of chemicals into plants for real field studies.

\section{Measured field dissipation data for model set-up}

For the establishment of the simulation scenario, the model was applied to literature data from three field experiments where the dissipation of pesticides from plants was examined over time.

Triazophos. Li et al. [39] reported overall dissipation of triazophos in wheat. The field experiment was conducted in 2003 on a site near Beijing, China. The triazophos residues in the sampled plant components were measured two hours and 1, 3, 5, 7, 14, 21 and 30 days after application. For the comparison with results from this study, our model was implemented with the soil degradation rate reported by Liang et al. [40]. No measured degradation for triazophos in wheat plants was found in the literature. Daily temperature and precipitation data for Beijing (see Supporting Information, SI) during the reported growth season were used and the germination day was estimated based on records of the local temperature and a minimum wheat germination temperature of $4{ }^{\circ} \mathrm{C}$ [41].

Propiconazole. Bai and Liu [42] reported overall dissipation of propiconazole in wheat. The field experiment was conducted near Tianjin, China, between April and June 1984. During three experiments, wheat fields were treated twice within 30 days with 125, 250 and $500 \mathrm{~g} / \mathrm{ha}$. Samples were taken on the day of the application and 3,10, 19, 29 and 34 days after the application. For the comparison with results from this study, our model was implemented with the soil degradation rate 
reported by Bromilow et al. [43] and the metabolic degradation rate for propiconazole in wheat reported by Owen et al. [44]. Daily temperature and precipitation data for Beijing, China, were used.

Tralkoxydim. Srivastava et al. [45] reported dissipation of tralkoxydim from wheat. The field experiment was conducted in Pantnagar, India, from December 1991 to February 1992. Two experimental fields were treated with 400 and $800 \mathrm{~g} / \mathrm{ha}$, respectively. Samples were taken 1 hour and 1, 3, 7, 14, 28, 45 and 60 days after the application. The germination day was given in the description of the experiments. An average degradation rate in soil was derived from the Footprint database [46]. No degradation rate of tralkoxydim in wheat was found in the literature. Daily temperature and precipitation data for New Delhi, India, were used.

\section{Model scenarios for simulation of dissipation}

The model was applied to pesticides covering different target classes and a wide range of physicochemical properties. Data of 42 pesticides were chosen from the pesticide dissipation database provided by Fantke and Juraske [15] (Table S1). The data set includes herbicides, fungicides, insecticides and plant growth regulators applied to tomato and wheat, with seven pesticides simulated for both crop types. 56 different pesticide-plant combinations were simulated in two scenarios with 25 pesticides simulated in tomato fruit, eight pesticides in tomato leaves and 23 in wheat leaves.

Location. Two locations, Copenhagen and Shanghai, were simulated as virtual agricultural fields positioned near the two cities. Copenhagen $\left(55.6761{ }^{\circ} \mathrm{N}, 12.568{ }^{\circ} \mathrm{E}\right)$ is located on the eastern coast of the island Zealand in Denmark and has a temperate climate. Shanghai $\left(31.2000{ }^{\circ} \mathrm{N}, 121.5000{ }^{\circ} \mathrm{E}\right)$ is located on the Yangtze River delta on the eastern Chinese coastline near the Pacific Ocean and has a subtropical climate. A description of the metrological data [47] can be found in the SI.

Crops. The two crop types selected for the simulations are wheat (Triticum aestivum L.) and tomato (Solanum lycopersicum). In the most recent world production estimates of the Food and Agriculture Organization of the United Nations, the global production of wheat for 2014 is 707 million tons [48]. The combined worldwide production of tomato exceeded 160 million tons in 2012 [49]. Data for the crop-specific parameters for wheat simulations were taken from [34], for tomatoes from $[14,50]$ and cell data from [51]. 
Initial mass distribution. The distribution of the applied active ingredient sprayed on plant and soil is based on the crop interception factors suggested by the FOCUS group [52], where an interception coefficient, depending on the growth stage, of $25 \%$ for wheat and $50 \%$ for tomato is suggested. A similar interception coefficient for wheat was found by Bai and Liu [42]. All active ingredients were uniformly distributed to the above-surface plant compartments, weighted with their specific surface area at the time of application.

Chemicals. A list of the 42 selected pesticides with their chemical class and physical and chemical properties can be found in the SI (Table S1). The chemical properties range from $\log \mathrm{K}_{\mathrm{OW}}-3.8$ (chlormequat, growth regulator) to 6.6 (cypermethrin, insecticide) and molar mass $\mathrm{M}$ from 141.1 $\mathrm{g} / \mathrm{mol}$ (methamidophos, insecticide) to $682.3 \mathrm{~g} / \mathrm{mol}$ (flubendiamide, insecticide) and thus cover a wide chemical space.

Overall dissipation rate. The simulated overall dissipation rates of each modeled compartment were calculated as pseudo-first order loss rates from the peak concentrations of the compartments and the concentrations at the $75^{\text {th }}$ percent dissipation. If the simulation period expired before reaching the $75^{\text {th }}$ percent dissipation, the concentration at the end of the simulation period was used. The individual loss rates of the compartments were calculated from the average of the rates of a given process over a seven day period, starting at the day of pesticide application. The calculated dissipation rates were compared to experimental rates collected from literature [15] (SI Tables S2 and S3).

\section{Significance of loss processes}

To examine the significance of three key physical and chemical properties of the pesticides on the distribution of the individual dissipation processes, nine chemicals with high/low values of the three key properties $\mathrm{K}_{\mathrm{OW}}, \mathrm{K}_{\mathrm{Aw}}$ and molar mass $\mathrm{M}$ were simulated. These are phorate, penconazole, chlorothalonil, propiconazole, azoxystrobin, cyfluthrin and methomyl plus one theoretical chemical with mean values of the three parameters from the 42 chemicals simulated in the current study and the fictive chemical fantene (low $\log \mathrm{K}_{\mathrm{OW}}=1.5$, high $\log \mathrm{K}_{\mathrm{AW}}=-5$ and $\mathrm{M}=450 \mathrm{~g} / \mathrm{mol}$ ). 


\section{Model performance}

Figure 1 shows the simulation results compared to the reported results from three field dissipation studies. Figure 1a shows the residues of the insecticide triazophos after the application on wheat [39]. The input of active ingredient (39.6 g/ha intercepted by leaves) was calculated from the measured initial concentration of pesticide in the crop, to avoid false mass balances. The initial concentration in the leaves was $19.4 \mathrm{mg} / \mathrm{kg}$ fresh weight (fw), and the mass of leaves at the time of application (day 46 after plant growth started) was $0.204 \mathrm{~kg}$. Subsequently, the calculated input for the leaf compartment is $3.95 \mathrm{mg}$. The remainder of the applied pesticide was input into the soil. Therefore, the peak of the modeled concentrations of the leaf compartments is identical with the peak of the measured concentrations (Fig. 1a). The modeled dissipation of triazophos is lower than the measurements. Assuming pseudo-first order loss, Li et al. [39] fitted a dissipation half-life of 5.59 days. The simulated half-life in leaf due to non-degradation loss processes alone is 9.59 days, nearly twice as long as the fitted dissipation half-life from the measurement study that includes degradation.

Figures $1 \mathrm{~b}$ and $1 \mathrm{c}$ show the measured and the simulated leaf concentrations of the herbicide tralkoxydim after a low and high dose application of 400 and $800 \mathrm{~g} / \mathrm{ha}$, respectively. The peaks of the measured concentrations of 0.27 and $0.55 \mathrm{mg} / \mathrm{kg}$ for the two scenarios occur with the application of the pesticide, whereas the peaks for the two simulated concentrations occur five days later and are 0.34 and $0.68 \mathrm{mg} / \mathrm{kg}$ fw for the low and high dose application, respectively. This delay is due to calculated uptake of active ingredient from soil to the leaf compartment after the application. Due to uptake from soil after application, the simulated dissipations curves are delayed compared to the measured data points. The input of the pesticide was adjusted as explained for Figure 1a. The calculated curve could be fitted but the underlying problem seems to be a disagreement of plant biomass. A mass balance with measured initial concentrations, applied mass of tralkoxydim and with $25 \%$ interception by the plants [52] reveals that the biomass at the time of the application (day 30) should have been $37 \mathrm{~kg} / \mathrm{m}^{2}$ (a value that is very unrealistic). In the model scenario, the mass of the leaf compartment at the day of application is only $0.09 \mathrm{~kg} / \mathrm{m}^{2}$, a difference of nearly a factor 400 . The true plant size was not measured or not given, a common problem in the simulation of measured field data. We decided to keep the top soil concentrations data of the authors and the plant scenario and accept the deviation caused by uncertain input data for plant 
biomass. According to Srivastava et al. [45], the dissipation of the low and high dose application measurements occurred with half-lives of 5.5 and 4.25 days, respectively. The simulated dissipation curves, without degradation and expressed as pseudo-first decay, gives for both simulations a halflife of 9.86 days.

Figures 1d-f show the measured and simulated concentrations of propiconazole in wheat after application of 125, 250 and $500 \mathrm{~g} / \mathrm{ha}$. In the field experiments the wheat crops were exposed to two applications of equal dimensions with a 30-day interval. For the three scenarios the pesticide interceptions given by Bai and Liu [42] (between $24.2 \%$ and $27.5 \%$ of the applied amount, in total $99.3 \mathrm{~g} / \mathrm{ha}$ to wheat straw and $310 \mathrm{~g} / \mathrm{ha}$ on top soil) were used instead of the FOCUS recommendations (25\% interception, [52]) but the difference is small. Different from the previous comparisons, it was not necessary to adjusted to the measured initial concentrations because the interception was given. The day the biomass of the model scenario reaches the biomass reported for the experiment is six days apart. This leads to a small overestimation of the leaf concentrations immediately after the application but the agreement later on is satisfying. The calculated peak concentrations are on average $154 \%$ of the measured peak concentrations. The 125 and $500 \mathrm{~g} / \mathrm{ha}$ scenarios show $160 \%$ of the measured peak concentrations, while the $250 \mathrm{~g} / \mathrm{ha}$ scenario shows $143 \%$ of the measured peak concentration. The experimental half-lives derived from the measured concentrations are 3.7, 3.7 and 5.9 days for the 125, 250 and $500 \mathrm{~g} /$ ha applications, respectively. The corresponding simulated half-life is 2.92 days for all three scenarios, and this includes the measured degradation in plants [44].

\section{Dissipation rates}

In Figure 2, the simulated dissipation rates from wheat and tomatoes of the 42 different pesticides (sorted by measured loss rates) are shown in comparison to experimental dissipation rates collected from literature [15]. The error bars denote the range of literature data for each individual pesticide (numbers to names see SI Table S1). The minimum, geometrical mean and maximum of literature data together with the calculated loss rates, the contribution of individual processes, and the difference between experimental and calculated loss rates is shown for each pesticide in the SI (Tables S2 and S3).

Most of the calculated loss rates - sum of growth dilution and volatilization minus uptake from soil - are in a narrow band between 0.05 and $0.1 \mathrm{~d}^{-1}$, while the measured loss rates (that additionally 
include degradation) vary in a much broader range. Ideally, all simulated dissipation rates should be equal to or slower than the experimentally derived dissipation rates because degradation is not included in the simulation, but adds to the loss processes.

Figure $2 \mathrm{ab}$ shows the simulated dissipation rates of 25 pesticides in tomato fruits near Copenhagen and Shanghai, respectively. Only four of the simulated dissipation rates in the Copenhagen scenario are higher than their corresponding experimental dissipation rates from literature (geometric mean), that are the rates of cyproconazole (no. 3), penconazole (no. 2), triazophos (no. 4) and phorate (no. 1). These four compounds have the lowest measured dissipation rates. The simulated rates of cyproconazole, triazophos and phorate also exceed the maximum dissipation rates given in literature. For the Shanghai scenario, the simulated rates of cyproconazole, penconazole, phorate, procymidone (no. 5) and triazophos exceed the geometrical mean of literature dissipation rates, while only the simulated rates of cyproconazole, phorate, procymidone and triazophos exceed the maximum literature dissipation rates. For both scenarios, most of the calculated dissipation is due to growth dilution. Growth dilution does not depend on the chemical but only on the crop growth and the time of application. Volatilization increases the loss only for a few compounds. Uptake of active ingredients from soil into plants is an input process that counter-acts loss, i.e. it decreases the simulated overall dissipation from leaves or fruits. For both scenarios the simulated dissipation rate of mancozeb (no. 17) is much lower than the mean experimental rate, and also those by growth dilution and volatilization alone. The reason for this outlier is a very high (calculated) uptake of mancozeb from soil. Mancozeb is a polar weak acid, and the estimated distribution coefficient between soil matrix and soil solution, $\mathrm{K}_{\mathrm{d}}$, as well as the root uptake are rather uncertain and $\mathrm{pH}$ dependent $[35,53,54]$. If uptake from soil is neglected, then calculated results are closer to the dissipation values of mancozeb from literature.

The dissipation rates of 25 pesticides in tomato fruits and of eight pesticides in tomato leaves from literature versus calculated dissipation are shown in Figure 2c (Copenhagen) and 2d (Shanghai scenario). Growth dilution is again the most relevant calculated dissipation process. For both scenarios, three of the 23 simulated pesticide rates are higher than the corresponding literature rates that are chlorothalonil (no. 31), diazinon (no. 36) and tebuconazole (no. 27). Two simulated rates of chlorothalonil and diazinon are considerably higher than their literature values in both scenarios, and high volatilization is the reason for the calculated rapid loss. The adsorption to leaves, which is indirectly proportional to volatilization from leaves, depends in the model on the ratio of the 
partition coefficients $\mathrm{K}_{\mathrm{OW}}$ and $\mathrm{K}_{\mathrm{AW}}$, and together with phorate (no. 1), these two compounds have the lowest value for this property of all (non-ionic) substances under consideration.

\section{Loss distribution}

Figure 3 illustrates the importance of the individual loss processes for the example of triazophos in the field experiment [39]. Both volatilization and growth dilution are important in this case. The effect of uptake from soil is a negative loss rate, i.e. input to the plant. Due to the non-steady precipitation events (rain every 7 days) the line is not smooth.

The contribution of individual loss processes of nine example compounds is shown in Table 1. Each compound in this list has a typical combination of the three key properties $\mathrm{K}_{\mathrm{OW}}, \mathrm{K}_{\mathrm{AW}}$ and $\mathrm{M}$ : each property was divided into a high and low category and eight pesticides were chosen to represent the spectrum of all 42 pesticides under investigation. A ninth, theoretical compound represents the average of the 42 compounds of the study. The scenario is tomato grown in Copenhagen.

The growth dilution for all nine chemicals in each of the four plant compartments is identical, 0.06 , 0.06, 0.07 and $0.13 \mathrm{~d}^{-1}$ for the compartments root, stem, leaves and fruits, respectively. The \% contribution to the overall loss, however, varies widely and depends on the magnitude of additional loss and transport processes. Growth dilution is most relevant for compound no. 8, cyfluthrin, which is the most insoluble, non-polar compound in the list. For the remaining compounds, which are all more soluble, the dominant loss process from roots and stems is translocation upwards. Uptake from soil balances the loss by translocation to a varying degree, most for compound no. 4 (the theoretical compound with $\log$ Kow 1.5) and no. 7 azoxystrobin, a non-volatile medium polar fungicide. The translocation ends in fruits and leaves, and growth dilution gains importance. It competes with volatilization to air, in particular for loss from leaves. For average compound no. 4, phorate (no. 2) and chlorothalonil (no. 5) volatilization is the dominant loss process. All three have a partition coefficient air-to-water $\mathrm{K}_{\mathrm{AW}} \geq 10^{-5} \mathrm{~L} / \mathrm{L}$, which is relatively high for pesticides. Overall, volatilization plays a minor role, compared to growth dilution and translocation, because most pesticides have by design a low $\mathrm{K}_{\mathrm{AW}}$ (Table SI 1).

Table 1 also includes the calculated impact of transfer from soil into plants on the overall dissipation from each plant compartment. Uptake from soil has, no surprise, the highest influence on the root and stem compartments. The highest transfer rate from soil was calculated for chemical 
no. 9, methomyl, which represents a pesticide with a low $\mathrm{K}_{\mathrm{Ow}}$, low $\mathrm{K}_{\mathrm{Aw}}$ and low molar mass, with a corresponding rapid uptake rate of $-8.70 \mathrm{~d}^{-1}$.

\section{Discussion}

Simulations. As seen in Figures 1a-c, all calculated concentrations are above the measured data points. This was expected because the three simulations do not include internal plant degradation. The simulation of penconazole (Figures 1d-f) fits best the measured data points even though it is the only compound where the input was not adjusted. But this simulation of penconazole includes a measured rate for internal plant degradation [44]. The dissipation of penconazole occurs slightly faster in the simulation than in the field experiments (Figures 1d-f), indicating an overestimated degradation rate. The plant variety used in the study by Owen et al. [44] is Triticum aestivum var. "Heines Koga II" whereas the exact variety of the Triticum aestivum used in the field experiments [42] is not given. The internal plant degradation rate found by Owen et al. [44] is higher than the dissipation rate found by Bai and Liu [42] but no other degradation rate of penconazole in wheat is reported in the literature.

Location matters. As can be seen in Figures 2a-f, the differences in measured dissipation rates (and thus perhaps also of degradation rates) can be considerable. In the simulations, the dissipation rate for Shanghai was in many cases less than that for Copenhagen, but only after uptake from soil was added. Both temperatures and precipitation are higher in Shanghai, and subsequently also transpiration and translocation from soil to plant are higher, leading to increased uptake of compound from soil to plant. This uptake from soil depends very much on the chemical properties. In Figure 1bc a strong effect of tralkoxydim uptake from soil leads to an increase and delay of the peak. This is not the case for triazophos (Figure 1a). Triazophos has a log $\mathrm{K}_{\mathrm{OW}}$ of 3.5 and sorbs stronger to the soil organic carbon than tralkoxydim with a $\log \mathrm{K}_{\mathrm{OW}}$ of 2.1. Methomyl had the highest change of loss rates due to uptake from soil in Table 1. In agricultural practice, the good translocation of methomyl from soil to plants allows the application of this insecticide by drip irrigation. A cascade plant uptake model like the one used in our study (but with only one soil compartment) was well able to calculate this uptake from soil accurately [25], which shows both that this process is of relevance for polar non-volatile compounds, and that the model is a valid tool for the prediction of uptake from soil. Simulations show that the relevance of this process depends on the interception (i.e., how much of the active ingredient reaches the soil at all) and thus on the growth stage; on the availability of water to the roots in the various soil layers (and therefore also 
on precipitation events before and after application); on the transpiration of the plants (and thus on leaf area, light and temperature); and on the sorption, leaching and degradation of the substance in soil. In summary, the underlying processes are complex, highly variable, site-specific and difficult to predict.

Higher temperature is typically associated with higher degradation rates $[18,25,55]$ but this did not affect the simulations not explicitly considering degradation in plants. FOCUS distinguishes between nine different scenarios that shall represent the span of agricultural practices in Europe [52]. However, field studies on pesticide degradation in soils gave little differences in degradation between Northern and Southern Europe and between North America and Europe [56,57]. The reason could be humidity: microbial degradation of pesticides in soil works best at optimal, medium water contents and is reduced in dry but also in very wet soil $[58,59]$.

Degradation rates. Degradation can be directly measured by use of labeled compounds [58], but this is nowadays not permitted for field conditions. Under the assumption that the model appropriately describes the dissipation processes of chemicals other than degradation, the difference between the empirical and the calculated loss rates represents degradation inside plants, either by enzymatic transformation or by photolysis. Then, the difference between the predicted loss (without degradation) and the experimentally determined loss (including degradation) gives the unknown degradation. This difference between predicted dissipation and the geometric mean of experimentally determined values from literature varies greatly between the 42 modeled compounds (Figure 2 or SI Tables S2 and S3). For most compounds, measured loss rates are clearly higher, which means that degradation is an important and often the dominant loss process. The average distribution between the loss processes for all 25 chemicals simulated in the Copenhagen tomato fruits scenario is $54.8 \%$ growth dilution, $1.6 \%$ volatilization and $43.6 \%$ (calculated) degradation in plants, respectively. The average distribution between the three loss rates for tomato fruits in the Shanghai scenario is similar with $56.4 \%, 1.2 \%$ and $42.3 \%$ for growth dilution, volatilization and degradation, respectively. For tomato leaves the equivalent distributions are $13 \%, 2 \%$ and $85 \%$ and $15 \%, 2 \%$ and $83 \%$ for the Copenhagen and Shanghai scenarios, respectively. For the wheat scenario the distribution between growth dilution, volatilization and degradation is $41 \%, 67 \%$ and $-8 \%$ for the Copenhagen scenario and 31\%, 39\% and 30\% for the Shanghai scenario.

As reported, the simulated loss rates from tomato fruits of the four chemicals cyproconazole, penconazole, phorate and triazophos exceed the geometrical mean of the literature rates, and this 
leads to negative loss percentages for degradation and skews the average distribution. Without, the numbers for dissipation from tomato fruits are $37.1 \%, 0.5 \%$ and $62.4 \%$ growth dilution, volatilization and degradation for the Copenhagen scenario and 40\%, 0\% and 60\% for the Shanghai scenarios. The corrected values for wheat are $27 \%, 5 \%$ and $68 \%$ growth dilution, volatilization and degradation for the Copenhagen scenario and $21 \%, 3 \%$ and $76 \%$ for the Shanghai scenario. These numbers show that degradation of pesticides in plants will usually be the main dissipation process, closely followed (and often exceeded) by growth dilution. Most pesticides have a rather low vapor pressure, because this increases their residence time on plant surfaces, and thus volatilization is of little relevance for this kind of compounds.

Bound residues and metabolites. Plants are well known to incorporate pesticides into bound and non-extractable residues that are not accessible to standard analysis [60]. This is because plants often use conjugation reactions for detoxification, and vacuolization or deposition in cell walls replace excretion processes [28]. These bound residues may therefore still pose a risk to consumers and deserve consideration in risk assessment [60]. Contrary, dissipation by growth dilution or volatilization does not lead to bound residues. Risk assessments using a default, minimum dissipation rate based on the latter processes are therefore conservative and safe, and we recommend, in cases where no loss rate is known, to calculate the loss by these processes.

Other findings. Previous studies quantifying the effect of growth dilution found conflicting results. Miles et al. [24] found that effect of growth dilution was of minor importance for the short-lived residues of malathion ( $\left.\log \mathrm{K}_{\mathrm{OW}} 2.75\right)$ but relevant for the more persistent methoxychlor $\left(\log \mathrm{K}_{\mathrm{OW}}\right.$ 5.83) [55]. Hopkins et al. [23] gives an average reduction by growth dilution of $60-80 \%$ on alfalfa within four to six weeks after application. Both Miles et al. [24] and Génard et al. [61] note the importance of the time of application (i.e. the growth stage) for the relevance and amount of growth dilution. This is confirmed by the model simulations, where growth of the crops is expressed by the logistic growth function [34,50]. Growth dilution is highest during the initial, exponential growth phase and slows down towards ripening.

Fantke et al. [18] developed a regression model for the estimation of pesticide dissipation half-lives (including degradation) from substance properties, plant characteristics and environmental conditions including temperature. $95 \%$ of the predicted half-lives were within a factor 4.5 of the reported half-lives taken from Fantke and Juraske [15]. 


\section{Conclusions}

In this study we parameterized a coupled dynamic model for the simulation of neutral and ionizable organic compounds in soil, soil water and crops for the application and residence of pesticides after spray application on wheat and tomatoes in Copenhagen and Shanghai.

The comparison to measured residues in leaves and fruits showed reasonable dissipation results which were - with few exceptions - slower than experimental loss rates from experimental field studies. This can be explained by the metabolism and degradation of pesticides in plants which were disregarded in the simulations. From the difference to measured dissipation of 42 pesticides, we thus quantified the contribution of degradation, growth dilution and volatilization to the overall loss of pesticides from plants.

The average distribution between the growth dilution and the volatilization rate for the calculated dissipation rates from tomato fruits showed the growth dilution to be far more significant than volatilization, while this latter process was of higher relevance for leaves. The average reduction in residual concentrations in tomato fruits by growth dilution was found to be $37 \%$ of the overall dissipation. For tomato leaves the average reduction of pesticide concentration by growth dilution was $13 \%$, and in wheat $21 \%$. Volatilization contributed in all simulation scenarios with up to $5 \%$ only. Growth dilution is thus the next most important dissipation process, after degradation, for the reduction of the pesticide residues and the crops studied. Uptake of active compound from soil to plant leads to a negative dissipation process (i.e. a gain) that is difficult to quantify because it depends largely on interception, precipitation and plant stage. The process is in particular relevant for soluble compounds. For the root and stem compartments, translocation of residues by the transpiration stream in and out is of very high importance, depending on the adsorption of the studied compounds. The process increases with decreasing $\mathrm{K}_{\mathrm{OW}}$.

It finally became obvious that the number of studies published with sufficient data for a comparison to simulations is small. In particular plant properties often lack but are of importance [62]. This hampers the development and validation of predictive relationships and models.

\section{Acknowledgements}

This work was financially supported by the Marie Curie project Quan-Tox (grant agreement no. 631910) funded by the European Commission under the Seventh Framework Programme. 


\section{References}

[1] J. Cooper and H. Dobson, The benefits of pesticides to mankind and the environment, Crop Prot. 26 (2007), pp. 1337-1348.

[2] D. Pimentel, H. Acquay, M. Biltonen, P. Rice, M. Silva, J. Nelson, V. Lipner, S. Giordano, A. Horowitz and M. D'Amore, Environmental and Economic Costs of Pesticide Use, Bioscience 42 (1992), pp. 750-760.

[3] M. W. Aktar, D. Sengupta and A. Chowdhury, Impact of pesticides use in agriculture: their benefits and hazards, Interdiscip. Toxicol. 2 (2009), pp. 1-12.

[4] F. P. Carvalho, Agriculture, pesticides, food security and food safety, Environ. Sci. Policy 9 (2011), pp. 685-692.

[5] K. L. Bassil, C. Vakil, M. Sanborn, D. C. Cole, J. S. Kaur and K. J. Kerr, Cancer health effects of pesticides: systematic review, Can. Fam. Physician 53 (2007), pp. 1704-1711.

[6] J. R. Coats and H. Yamamoto, Environmental Fate and Effects of Pesticides, American Chemical Society, Washington, D.C., 2003.

[7] J. Stenersen, Chemical Pesticides: Mode of Action and Toxicology, CRC Press, Taylor and Francis Group, Boca Raton, Florida, 2004.

[8] P. Fantke, R. Friedrich and O. Jolliet, Health impact and damage cost assessment of pesticides in Europe, Environ. Int. 49 (2012), pp. 9-17.

[9] D. Hamilton and S. Crossley, Pesticide Residues in Food and Drinking Water: Human Exposure and Risks, John Wiley and Sons, Inc., Chichester, 2004.

[10] EFSA European Food Safety Authority, 2008 Annual Report on Pesticide Residues according to Article 32 of Regulation (EC) No 396/2005, European Food Safety Authority, The EFSA Journal 8(7): 1646, Parma, 2010.

[11] P. Fantke, R. Charles, L. F. de Alencastro, R. Friedrich and O. Jolliet, Plant uptake of pesticides and human health: Dynamic modeling of residues in wheat and ingestion intake, Chemosphere 85 (2011), pp. 1639-1647.

[12] C. D. Collins, I. Martin and W. Doucette, Plant uptake of xenobiotics, in Organic Xenobiotics and Plants: From Mode of Action to Ecophysiology, P. Schröder and C. D. Collins, eds., Springer Press, Dordrecht, 2011, pp. 3-16.

[13] S. Trapp and C. N. Legind, Uptake of organic contaminants from soil into vegetables and fruits, in Dealing with Contaminated Sites - From Theory towards Practical Application, F. A. Swartjes, ed., Springer Press, Dordrecht, 2011, pp. 369-408.

[14] S. Trapp and J. C. Mc Farlane, Plant Contamination: Modeling and Simulation of Organic Chemical Processes, Lewis Publishers, Boca Raton, Florida, U.S., 1995. 
[15] P. Fantke and R. Juraske, Variability of pesticide dissipation half-lives in plants, Environ. Sci. Technol. 47 (2013), pp. 3548-3562.

[16] R. Juraske, A. Assumpcio, F. Castells. Estimating half-lives of pesticides in/on vegetation for use in multimedia fate and exposure models. Chemosphere 70 (2008) 1748-1755.

[17] P.J. Thomas, P. Mineau. Determining pesticide foliar half-lives from soil half-life value: Not so 'cut-and-dry'. Letter to the editor, Chemosphere 84 (2011) 1531-1533.

[18] P. Fantke, B.W. Gillespie, R. Juraske and O. Jolliet, Estimating half-lives for pesticide dissipation from plants, Environ. Sci. Technol. 48 (2014), pp. 8588-8602.

[19] C. Collins, M. Fryer and A. Grosso, Plant uptake of non-ionic organic chemicals, Environ. Sci. Technol. 40 (2006), pp. 45-52.

[20] F. van den Berg, R. Kubiak, W. G. Benjey, M. S. Majewski, S. R. Yates, G. L. Reeves, J. H. Smelt and A. M. A. van der Linden, Emission of pesticides into the air, Water Air Soil Poll. 115 (1999), pp. 195-218.

[21] A. Wolters, M. Leistra, V. Linnemann, J. H. Smelt, F. van den Berg, M. Klein, N. Jarvis, J. J. T. I. Boesten and H. Vereecken, "Pesticide volatilisation from plants: Improvement of the PEARL, PELMO and MACRO Models," in Pesticide in air, plant, soil \& water system : Proceedings of the 12. Symposium Pesticide Chemistry, June 4-6, 2003, Piacenza, Italia, 2003, pp. 985-994.

[22] M. Riederer. Partitioning and transport of organic chemicals between the atmospheric environment and leaves, in Plant Contamination - Modeling and Simulation of Organic Chemical Processes, S. Trapp and J. C. McFarlane, eds., Lewis Publisher, Boca Raton, 1995, pp. $153-190$.

[23] L. Hopkins, L. B. Norton and G. G. Gyrisco, Persistence of insecticide residues on forage crops, J. Econ. Entomol. 45 (1952), pp. 213-218.

[24] J. R. W. Miles, W. W. Sans, H. B. Wressell and G. F. Manson, Growth-dilution as a factor in the decline of pesticide residues on alfalfa-grass forage, Can. J. Plant Sci. 44 (1964), pp. 3741.

[25] C. N. Legind, C. M. Kennedy, A. Rein, N. Snyder and S. Trapp, Dynamic plant uptake model applied for drip irrigation of an insecticide to pepper fruit plants, Pest Manag. Sci. 67 (2011), pp. 521-527.

[26] P. Fantke, P. Wieland, R. Juraske, G. Shaddick, E. Sevigné, R. Friedrich and O. Jolliet, Parameterization models for pesticide exposure via crop consumption, Environ. Sci. Technol. 46 (2012), pp. 12864-12872.

[27] P. Fantke, P. Wieland, C. Wannaz, R. Friedrich and O. Jolliet, Dynamics of pesticide uptake into plants: From system functioning to parsimonious modeling, Environ. Modell. Softw. 40 (2013), pp. 316-324. 
[28] D. Komossa, C. Langebartels, and H.J. Sandermann, Metabolic processes for organic chemicals in plants, in Plant Contamination - Modeling and Simulation of Organic Chemical Processes, S. Trapp and J. C. McFarlane, eds., Lewis Publisher, Boca Raton, 1995, pp. 69 103.

[29] Trapp S, Matthies M, Scheunert I and Topp EM (1990): Modeling the bioconcentration of organic chemicals in plants. Environmental Science and Technology 24 (8), 1246-1252.

[30] S. H. Emerman, The Tipping Bucket equations as a model for macropore flow, J. Hydrol. 171 (1995), pp. 23-47.

[31] S. Trapp and M. Matthies, Chemodynamics and Environmental Modeling, Springer, Berlin, 1998.

[32] C. N. Legind, A. Rein, J. Serre, V. Brochier, C.-S. Hausin, P. Cambier, S. Houot, and S. Trapp, Simultaneous simulations of uptake in plants and leaching to groundwater of cadmium and lead for arable land amended with compost or farmyard manure, PLoS One 7 (2012).

[33] S. Trapp, Fruit tree model for uptake of organic compounds from soil and air, SAR QSAR Environ. Res. 18 (2007), pp. 367-387.

[34] A. Rein, C. N. Legind, and S. Trapp, New concepts for dynamic plant uptake models, SAR QSAR Environ. Res. 22 (2011), pp. 191-215.

[35] S. Trapp, Bioaccumulation of polar and ionizable compounds in plants, in Ecotoxicology Modeling, J. Devillers, ed., Springer US, Boston, 2009, pp. 299-353.

[36] S. Trapp and T. Eggen, Simulation of the plant uptake of organophosphates and other emerging pollutants for greenhouse experiments and field conditions, Environ. Sci. Pollut. Res. Int. 20 (2013), pp. 4018-4029.

[37] M. Højrup, Fate modeling of human pharmaceutical excreted to wastewater, MSc. thesis, Technical University of Denmark, 2014.

[38] R. S. Prosser, S. Trapp, and P. K. Sibley, Modeling uptake of selected pharmaceuticals and personal care products into food crops from biosolids-amended soil, Environ. Sci. Technol. 48 (2014), pp. 11397-11404.

[39] W. Li, S.-P. Qiu, and Y.-J. Wu, Triazophos residues and dissipation rates in wheat crops and soil, Ecotoxicol. Environ. Saf. 69 (2008), pp. 312-316.

[40] B. Liang, C. Yang, M. Gong, Y. Zhao, J. Zhang, C. Zhu, J. Jiang, and S. Li, Adsorption and degradation of triazophos, chlorpyrifos and their main hydrolytic metabolites in paddy soil from Chaohu Lake, China, J. Environ. Manage. 92 (2011), pp. 2229-2234.

[41] J. Herbek and C. Lee, A comprehensive guide to wheat management in Kentucky, Grain Crops Extension, University of Kentucky (2009), available at http://www.uky.edu/Ag/GrainCrops/ID125Section2.html. 
[42] Q.-Y. Q. Bai and C. C.-W. Liu, Dissipation of propiconazole residues in and on wheat (Triticum aestivum L.), Pestic. Sci. 19 (1987), pp. 229-234.

[43] R. Bromilow, A. Evans, and P. Nicholls, Factors affecting degradation rates of five triazole fungicides in two soil types: 2. field studies, Pestic. Sci. 55 (1999), pp. 1135-1142.

[44] W. J. Owen and B. Donzel, Oxidative degradation of chlortoluron, propiconazole, and metalaxyl in suspension cultures of various crop plants, Pestic. Biochem. Physiol. 89 (1986), pp. 75-89.

[45] A. Srivastava, K. Gupta, and G. Singh, Dissipation of tralkoxydim herbicide from wheat crop and soil under subtropical conditions, Pestic. Sci. 43 (1995), pp. 53-55.

[46] Footprint, The pesticide properties database (PPDB 2.0). Database collated by the University of Hertfordshire as part of the EU-funded FOOTPRINT project (FP6-SSP022704), University of Hertfordshire, 2015.

[47] Climatemps, Average Weather and Climate guide, 2013, available at http://www.climatemps.com/.

[48] FAO, Crop prospects and food situation, no. 2 2014, Food and Agriculture Organization of the United Nations, Rome, Italy, 2014.

[49] FAOSTAT, FAOSTAT, Food and Agriculture Organization of the United Nations Statistical Division, 2014, available at http://faostat.fao.org/.

[50] P. Fantke, R. Juraske, A. Antón, R. Freidrich, and O. Jolliet, Dynamic multicrop model to characterize impacts of pesticides in food, Environ. Sci. Technol. 45 (2011), pp. 8842-8849.

[51] C.N. Legind, S. Trapp. Prediction of uptake into food crops/accumulation in fish, as part of human exposure assessment. Deliverable 1.5 to the project PHARMAS Ecological and human health risk assessments of antibiotics and anti-cancer drugs found in the environment. February 2015 available at http://www.pharmas-eu.net/download/deliverables

[52] FOCUS, Generic guidance for FOCUS groundwater scenarios, European Commission, 2002, available at http://focus.jrc.ec.europa.eu/.

[53] A. Franco and S. Trapp, Estimation of the soil-water partition coefficient normalized to organic carbon for ionizable organic chemicals, Environ. Toxicol. Chem. 27 (2008), pp. 1995-2004.

[54] A. Franco, W. Fu and S. Trapp, Influence of soil pH on the sorption of ionisable chemicals: modelling advances. Environ. Toxicol. Chem. 28 (2009), pp. 458-464.

[55] EFSA Panel on Plant Protection Products and their Residues, Opinion on a request from EFSA related to the default $Q 10$ value used to describe the temperature effect on transformation rates of pesticides in soil 1 Scientific Opinion of the Panel on Plant Protection Products and their Residues ( PPR-Panel ) Adopted, EFSA J. 622 (2007), pp. 132. 
[56] R. Sur, Comparison of Terrestrial Field Dissipation Half-Lives of Pesticides and Their Metabolites Across Europe, Bayer CropScience LP, SETAC Europe $24^{\text {th }}$ Annual Meeting, 2014.

[57] R. Sur, Terrestrial Field Degradation Based on Soil, Climatic, and Geographic Factors, in Non-First Order Degradation and Time-Dependent Sorption of Organic Chemicals in Soil, W. Chen, A. Sabljic, S. A. Cryer, and R. S. Kookana, eds. American Chemical Society, 2014, pp. 39-56.

[58] M. Kästner, K.M. Nowak, A. Miltner, S. Trapp, A. Schäffer. Classification and modelling of non-extractable residue (NER) formation of xenobiotics in soil - a synthesis. Critical Reviews Environ. Sci. Technol. 44(19) (2013), 1-65.

[59] A. Dechesne, G. Wang, G. Gülez, D. Or, B. F. Smets. Hydration-controlled bacterial motility and dispersal on surfaces. PNAS 107(32), (2010), 14369-14372, doi: 10.1073/pnas.1008392107.

[60] H. Sandermann jr. Review Bound and unextractable pesticidal plant residues: chemical characterization and consumer exposure. Pest Manage. Sci. 60 (2004), pp. 613-623.

[61] M. Génard, V. Baldazzi, and Y. Gibon, Metabolic studies in plant organs: don't forget dilution by growth, Front. Plant Sci. 5 (2014).

[62] S. Trapp. Calibration of a plant uptake model with plant- and site-specific data for uptake of chlorinated organic compounds into radish. Environ. Sci. Technol. DOI: 10.1021/es503437p 

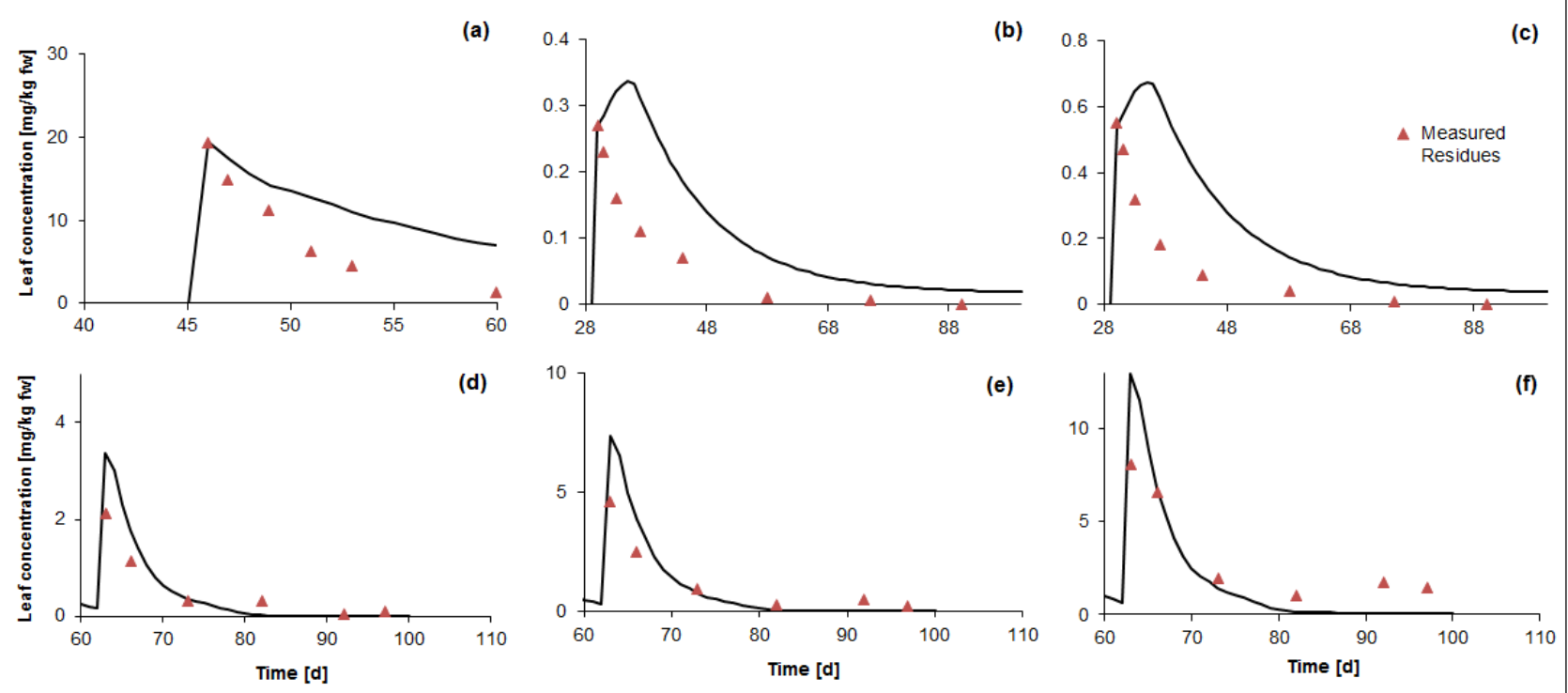

614 Figure 1. Measured (symbols) and simulated (solid line) concentration in leaves (mg pesticide per $615 \mathrm{~kg}$ sampled plant fresh weight) versus time (days after germination); a) triazophos [39], b) and c) 616 tralkoxydim [45], d), e) and f) penconazole [42]. 

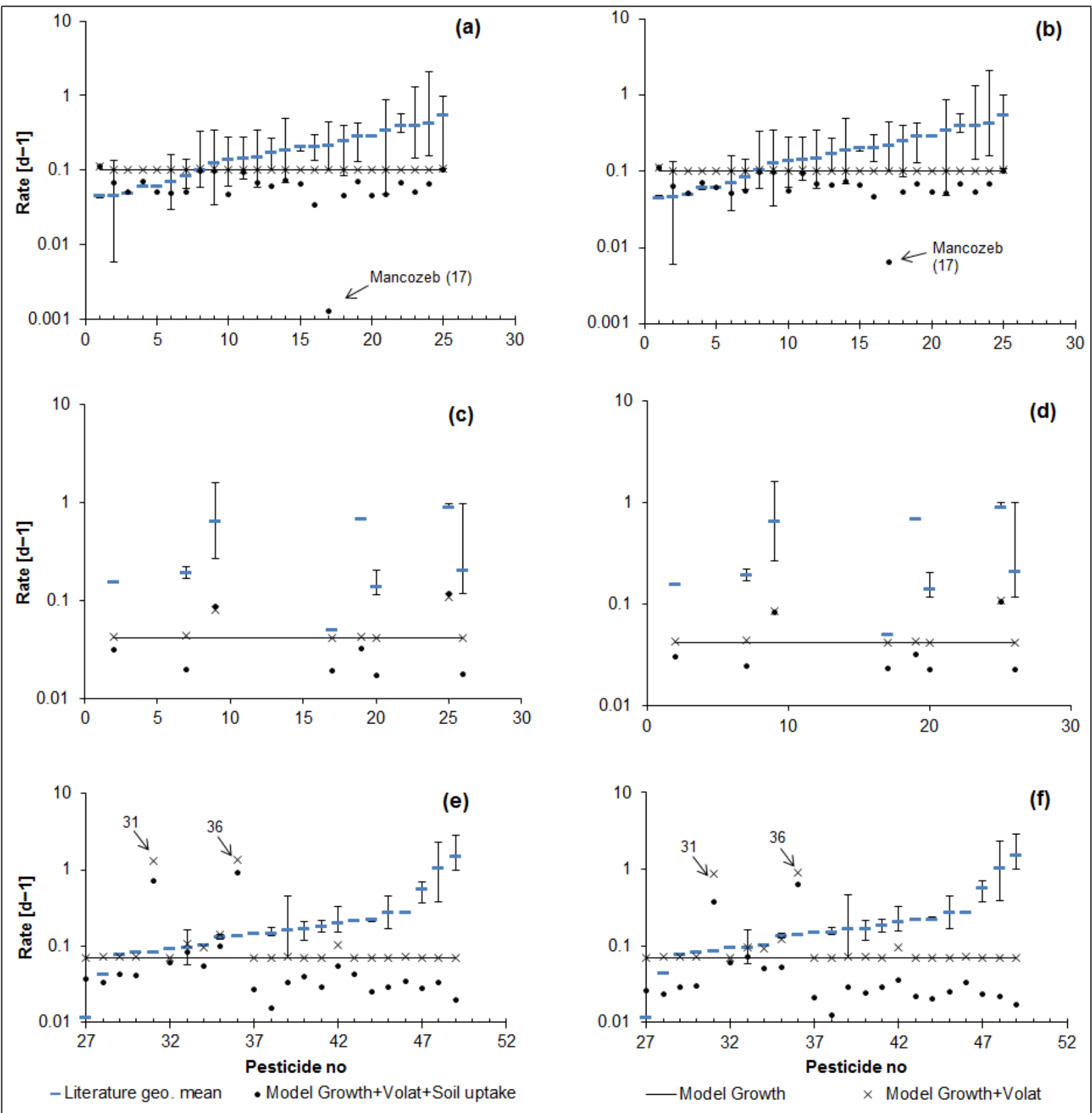

619 Figure 2. Geometric mean of experimentally derived dissipation rates [15, SI Tables S2 and S3] 620 compared with simulated dissipation rates for growth dilution, volatilization and overall dissipation 621 including uptake from soil. Error bars denote minimum and maximum of reported experimental 622 data. Scenarios: a) tomato fruit in Copenhagen b) tomato fruit in Shanghai c) tomato leaf in 623 Copenhagen d) tomato leaf in Shanghai e) wheat leaf in Copenhagen f) wheat leaf in Shanghai. 624 Arrows in a) and b) denote mancozeb (17) with high uptake from soil, in e) and f) chlorothalonil 625 (31) and diazinon (36), with high volatilization from leaves, see text. 


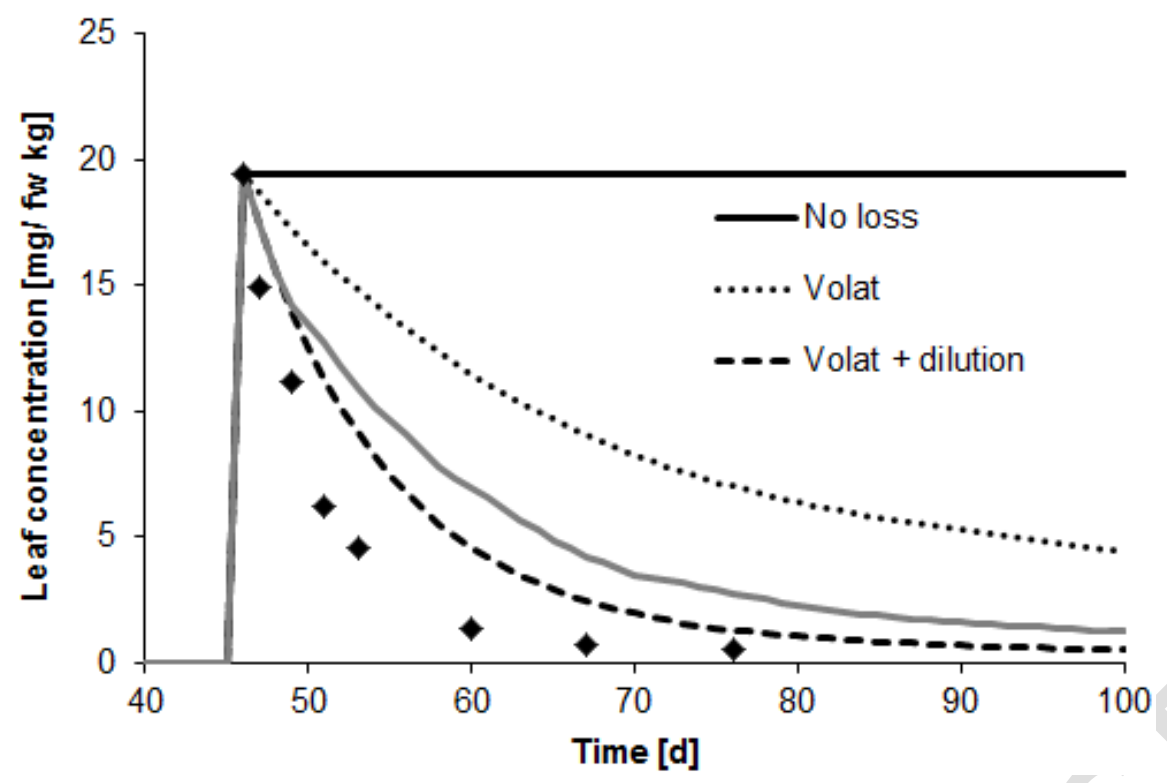

628

629 Figure 3. Simulated loss, step-by-step addition of processes for triazophos compared to measured 630 residues in wheat straw [31]. 
Table 1. Process rates and percentage loss from each plant compartment (tomato, Copenhagen scenario) for nine chemicals illustrating the influence of the chemical properties (SI Table S4) on dissipation. Negative loss rates and percentages indicate input into the plant.

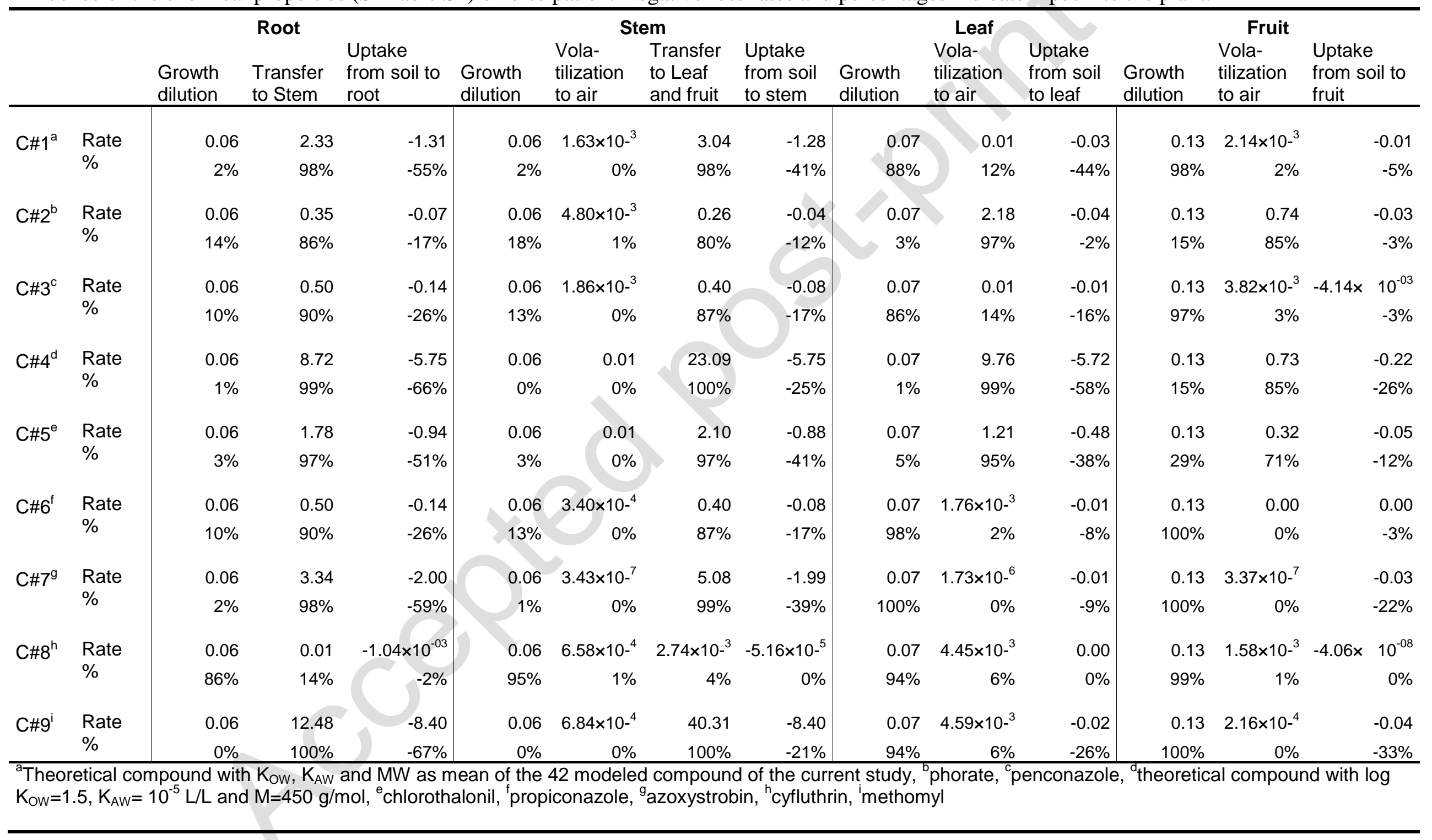

